J Arid Land (2015) 7(5): 675

doi: 10.1007/s40333-015-0012-5

jal.xjegi.com; www.springer.com/40333

\title{
Erratum to: Nighttime sap flow and its driving forces for Populus euphratica in a desert riparian forest, Northwest China
}

\author{
SI Jianhua ${ }^{1,2 *}$, FENG Qi ${ }^{1,2}$, YU Tengfei ${ }^{1,2}$, ZHAO Chunyan $^{1}$ \\ ${ }^{1}$ Alxa Desert Eco-hydrology Experimental Research Station, Cold and Arid Regions Environmental and Engineering Research Institute, \\ Chinese Academy of Sciences, Lanzhou 730000, China; \\ ${ }^{2}$ Gansu Hydrology and Water Resources Engineering Center, Lanzhou 730000, China \\ Published online: 10 May 2015 \\ CXXinjiang Institute of Ecology and Geography, Chinese Academy of Sciences, Science Press and Springer-Verlag Berlin Hei- \\ delberg 2015
}

\section{Erratum to: J Arid Land DOI 10.1007/s40333-015-0009-0}

In this Erratum, we correct three references in which the first and last names of their authors are reversed in order. The corrections are as follows:

Escalona J M, Fuentes S, Tomás M, et al. 2013. Responses of leaf night transpiration to drought stress in Vitis vinifera L. Agricultural Water Management, 118: 50-58.

Rosado B H P, Oliveira R S, Joly C A, et al. 2012.
Diversity in nighttime transpiration behavior of woody species of the Atlantic Rain Forest, Brazil. Agricultural and Forest Meteorology, 158-159: 13-20.

Tateishi M, Kumagai T, Utsumi Y, et al. 2008. Spatial variations in xylem sap flux density in evergreen oak trees with radial-porous wood: comparisons with anatomical observations. Trees, 22: 23-30.

The online version of the original article can be found under doi: 10.1007/s40333-015-0009-0.

*Corresponding author: SI Jianhua (E-mail: jianhuas@1zb.ac.cn) 